\title{
Teaching German Grammar: Strictly for the Birds?
}

\author{
Erika Diehl (Geneva) and Bettina Boss (New South Wales)
}

Among foreign language teachers we probably all agree that teaching grammar can be an onerous and frustrating task. We may use textbooks with pedagogically sound learning sequences, a variety of attractive exercises designed to stimulate communication, targeted grammar tests which make us believe our students have understood and can apply the rules of the target language - as soon as the learners' attention shifts from a focus on form to a focus on meaning, all grammar practice seems to have been for the birds, or, as we say in German, "für die Katz" - for the cat, that is useless. $^{1}$

Not surprisingly, this all too common experience leads many teachers to conclude that yet more grammar practice is required. According to a recent European survey reported in Koenig (2001), more than $50 \%$ of the instruction in foreign language courses is devoted to grammar. If the language to be learnt is structurally as complex as German, foreign language teaching and learning can become pure drudgery - for a start, the inflection of the noun phrase is determined by three genders and four cases with a confusing inventory of morphemes including homonymous and polysemous forms. In addition, German word order seems to defy all common sense: the verbal complex is split and pulled apart, in subordinate clauses the subject comes first and the verb at the very end, and the canonical subject-verb sequence is an exception rather than the rule. Put briefly, German grammar appears to violate all the "operating principles" which according to Slobin (1973) are prerequisites for successful language acquisition.

But of course children in German-speaking countries learn their mother tongue as effectively as children with other first languages, and they generally do so without the slightest bit of help in the form of rules

\footnotetext{
${ }^{1}$ Cf. the title of Diehl et al. (2000): «Grammatikunterricht - Alles für der Katz ? ...», which reproduces this phrase with a typical learner error in case assignment.
} 
or explanations from their parents or caregivers who provide the input. Research into learning psychology suggests that children acquiring the often complex rules of their L1 make use of implicit knowledge, that is knowledge which can be activated spontaneously but cannot be made explicit (e.g. Berry and Dienes 1993, Bärenfänger 2002).

Foreign language pedagogy is based on the belief that the many detours occurring during first language acquisition can be avoided provided the learners have the cognitive skills needed to understand and articulate the structures and rules of the language they are learning. The rules then only need to be memorised and consolidated through exercises to enable the students to apply them productively. Neither teachers nor students doubt the effectiveness of this process, although time and again it fails them.

Maybe we should ask why it is that explicit grammatical knowledge is of so little use in real-life situations when learners want to communicate in writing, or, harder still, in speaking. Are our teaching methods ineffective, have our students forgotten how to learn, is the German language just too hard? Or should we be asking ourselves whether instructed language acquisition is governed by universal processes analogous to those of first language acquisition? Is it conceivable that even classroom learners have to work out the structure of a new language for themselves and that our explanations and exercises are not as helpful as we had assumed?

Second language acquisition research has pursued these and similar questions during the last decades, with some astonishing results (for an overview see Ellis 1994, also Jansen this volume). These brought with them a change of perspective in second language research: researchers started to investigate how learners process the input, such as the foreign language grammar they are exposed to. How do they build up their competence in the target language? What is the relationship between the grammar curriculum of the schools and the structures acquired by the students? 
These are the questions that motivated the DiGS research project - the acronym DiGS stands for "Deutsch in Genfer Schulen" (German in Geneva schools). Designed to contribute equally to language acquisition research and to foreign language teaching pedagogy, the project had a dual aim:

1. to test the hypothesis that the instructed acquisition of German grammar is subject to internal processes largely impervious to external intervention;

2. to explore the pedagogical implications of the project findings and make recommendations for teachers and course designers of German as a foreign language.

Although in terms of research methodology, the DiGS project resembles previous studies dealing with the acquisition of German as a second or foreign language, it differs from them in exploring a wider range of questions, using a larger corpus and using written, not oral data. Because of its scope, the project was carried out by five linguists from the University of Geneva and 35 teachers from every level of the Geneva school system.

The data collected consisted of 1800 German texts written by 220 francophone school students of either sex, drawn from 30 classes at every level from year four to year 13 in the Geneva school system. During the two years of the data collection (1995/1996) each student contributed eight texts of "free writing" in German, which were analysed for verb and noun phrase morphology, as well as for word order. At the same time, the grammar taught in each class was recorded. The topics for the texts were designed so as to enable the students to use the grammatical structures they had been taught at that stage. In this way, it was possible to observe how they dealt with the new structures they learnt, how soon they used them productively and how long it took them to reach target-like mastery. According to the length of time this took the corresponding grammar rules were interpreted as more or less difficult to acquire; on the basis of the combined analyses of data from all subjects it was possible to 
determine universal sequences of acquisition in three areas of German grammar: verb morphology, word order (specifically the placement of the finite verb) and case assignment.

To cut a long story short: The findings of the project proved beyond doubt that although the Geneva students learned German grammar, this did not happen in the way they or their teachers had imagined. No student was able to absorb and process the structures he or she was taught and produce target-like utterances from the start, none kept pace with the rate at which new material was introduced in the classroom. Nevertheless, they made undeniable progress in their mastery of German morphology and syntax and despite some individual differences did this in such a uniform way that the researchers were led to assume similar cognitive processes to those found in first language acquisition. Specifically, all subjects acquired verb conjugation, the declension of the noun phrase and the position of the verb in the same order, which differed from that of the school curriculum; moreover, the strategies the subjects used were similar to those used in first language acquisition (cf. Bärenfänger 2002, Mills 1985). Needless to say, there were individual differences in the subjects' level of achievement, their preference for specific strategies and their rate of acquisition - but not in the order in which they acquired the structures in the three areas investigated. 
Learning phases in verbal morphology, word order and case assignment

(Cf. Diehl et al. (2000), p. 364, Tab. 55)

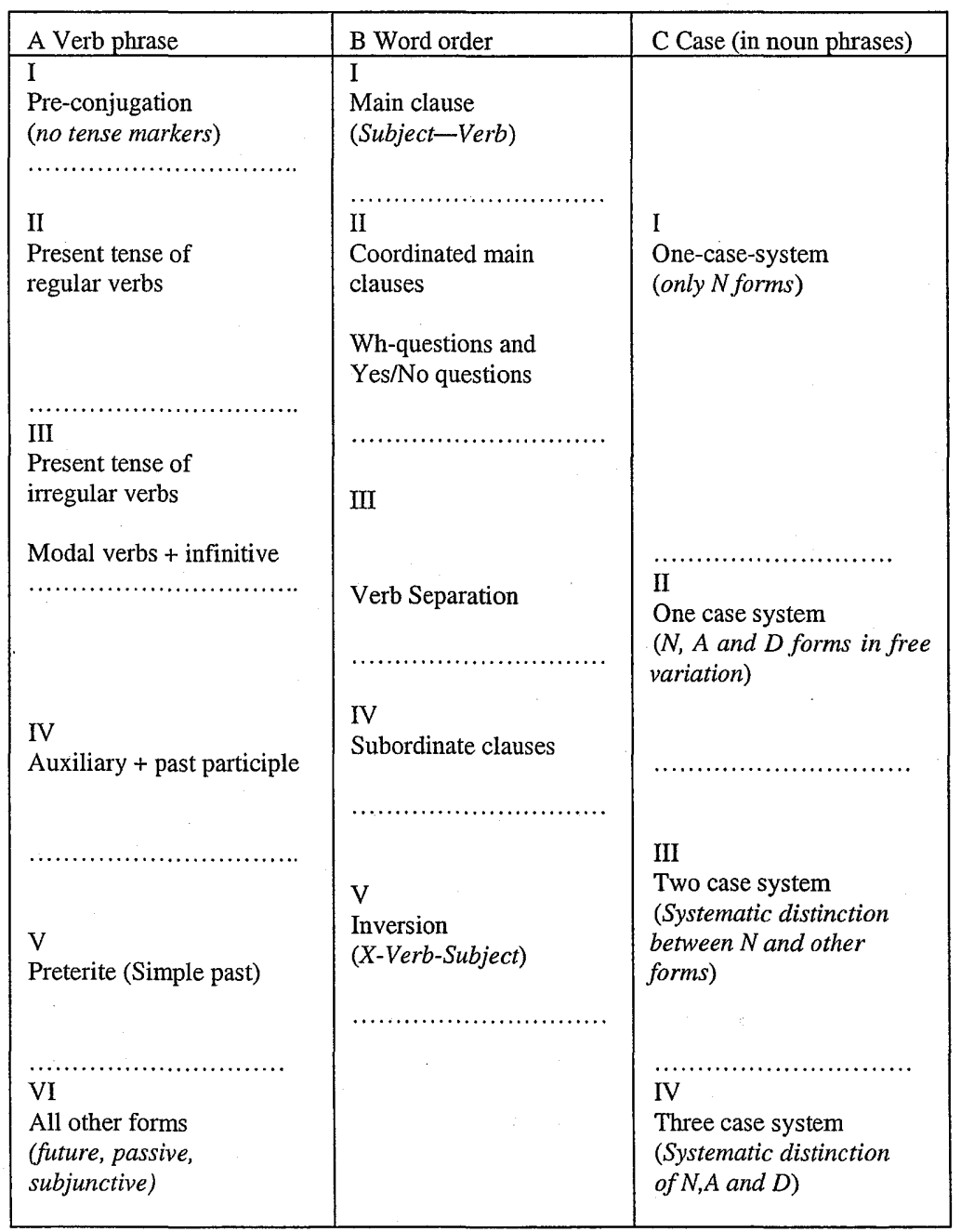


The table gives an overview of the sequences of acquisition Diehl and her colleagues established. It can be read vertically as well as horizontally: in vertical order it shows the sequence of learning phases observed in each area; read horizontally, it illustrates how a representative majority of subjects progressed through the three sequences concurrently. The dotted lines separating the learning phases horizontally allow for the fact that some subjects differed from the general pattern by progressing more quickly in either area A or B than indicated on the table; significantly, no student was found to make faster progress in the area of case assignment. Although the acquisition of gender and number assignment was investigated, no evidence of a universal sequence was found in these two areas.

A comparison of the three sequences with the order in which the relevant structures were taught shows the closest correspondence in the area of verb morphology; that is the students acquired the German verbal system more or less in the order in which it was introduced in the classroom. In the area of word order, subject verb inversion, in particular, was acquired much later than it was taught, and in the case system, there was an even more pronounced delay between instruction and acquisition.

To illustrate how the learning phases reached by an invidual learner at a particular stage in his acquisition of German can be determined, a sample from the data is presented and analysed as follows.

$\operatorname{Yvan}^{2}$ (The subject is retelling a picture story.)

"Her Wolf and Her Helmut haben am 12 Uhr gegessen. Suzammen, sie haben in die Haus gesprochen. Her Wolf hat ein Messer genommen und er hat gesagt: Wo sind die Diamanten? Her Helmut hat gesagt: Ich schweis es nicht! Her Wolf hat nich verstenden, und er hat töten her Helmut weil er hat dass Her Helmut möchte die Diamanten allein genommen gedenken. Er hat der Messer genommen (weil er hat mit dem Messer her Helmut getöten) und er ist in einem Park gefahren. In die Park er hat der Messer caché." hat der Assistent gesagt.

\footnotetext{
${ }^{2}$ The subject's name has been changed.
} 
"Gut, du bist intelligent, das ist richtig" hat Inspektor Snif gesagt.

Looking at the verbal forms in this text one can see that the learner produces four target-like perfect tense forms, while a further three (*verstenden; *gedenken; *getöten) suggest a tendency to overgeneralise the strong verb paradigm, possibly as a result of intensive training of these verbs in the classroom. One participle (caché) is supplied in French, presumably because the learner does not know the corresponding German verb verstecken. In two utterances the learner confuses the structure 'modal verb + infinitive' (a feature of learning phase III) with that of 'auxiliary + past participle' (er hat *töten; Her Helmut möchte ... *genommen). Despite this it can be said that he has reached phase IV (Auxiliary + past participle), which implies the earlier phases have been acquired as well. In fact the DiGS data frequently show that the beginning of a new phase coincides with a temporary confusion involving errors in areas acquired previously.

In the area of word order, we find that verb separation is produced correctly with one exception (er hat *töten Her Helmut), indicating that phase III is acquired. None of the subordinate clauses produced has the finite verb in final position (weil er *hat ... gedenken; dass Her Helmut *möchte ... genommen; weil er *hat ... getöten), although two of them are of such complexity that even more advanced learners might have found them challenging. As for subject-verb inversion, the target-like insertions (hat der Asisstent gesagt; hat Inspektor Snif gesagt) have to be interpreted as examples of $L 1$ transfer, since inversion in this context is obligatory in French. On the other hand, the fact that Yvan does not supply inversion after a preposed adverbial phrase (Suzammen, sie haben; In die Park er hat) suggests he cannot apply the rule productively. However, the fact that he produces subordinate clauses - though none of them target-like places him at the beginning of phase IV.

Looking at the examples of case assignment in this text, we find ambiguous forms (e.g. Her Wolf hat ein Messer genommen) as well as some where the nominative form is used in an accusative context (er hat töten her Helmut; er hat der Messer genommen). In fact, the utterances 
involving direct case assignment show no evidence that the learner can produce anything other than nominative forms. If, however, we include prepositional phrases in our analysis - with due caution, given their formulaic character - we can see that the learner does distinguish between "in einem Park" and "in die Park," which reveals some awareness of the rules determining the function of these morphological markers, although they are not applied correctly. Therefore one can conclude that this learner is in transition between phases I and II of the case system; indeed, a representative number of DiGS subjects were found to have reached phase IV in the verb system, concurrently with phase III or IV for word order and phase II for case assignment.

In addition to the sequences of acquisition described above, the DiGS data revealed the following typical strategies which learners tend to apply whenever they tackle a new structure:

- They begin by memorising chunks, formulaic expressions, prefabricated patterns, routines, language patterns, lexicalised phrases - a plethora of terms is used by researchers to describe this phenomenon which is attracting increasing attention (cf. Bärenfänger 2002). These memorised props, though not properly understood at first, constitute the raw material which will be used later to form hypotheses about the rules of the target language. As long as chunks occur in predictable contexts they are generally target-like, giving the false impression that the corresponding grammar rule is acquired.

- Once a certain number of chunks have been memorised, their further storage becomes uneconomical and the process of genuine acquisition can begin. In this phase individual forms and structures are chosen at random and overgeneralised in all contexts of a specific grammatical feature; for instance, the third person singular is used for all verb forms, nominative for all case markers, canonical word order for all sentence types. Of course, numerous errors occur now, since, depending on the number of different forms available, the chances of getting it right can be slim. 
- The next step in the acquisition process can be described as the progressive deconstruction of an initial rudimentary system, driven by input from the L2: the range of verb forms used increases, case morphology is developed, sentence structure becomes more flexible resulting in an even greater number of errors and sometimes a linguistic production resembling total chaos (Peltzer-Karpf and Zangl (1998) describe this phase appropriately as "turbulent"). However, there is evidence of developmental phases in each of the three areas examined and errors can generally be interpreted as the result of search strategies.

A further acquisition strategy, transfer from the L1, was observed exclusively in the area of word order, as demonstrated in the analysis of Yvan's text above.

It cannot be denied that research findings like the ones produced by the DiGS project raise serious questions about the way foreign languages are taught, regardless of the teaching methods used. Teachers may well ask what role is left for them to play if their students need to find the rules of the target language grammar by relying on their own strategies of acquisition. But paradoxical as it may seem, teachers who understand how a foreign language is acquired are better equipped to support their students' learning. The findings of the DiGS study suggest the following principles which should inform such an enlightened approach to foreign language teaching:

1. The force driving any acquisition - assuming the learners are motivated - is rich input in the target language. Outside the German-speaking countries teachers are the sole providers of that input; the more natural, authentic the input they can offer their students the better.

2. The second most important thing is the learners' output: teachers must give their students as many opportunities for communication in the target language as possible, be it ever so rudimentary and deficient. The more this communication approaches genuine, spontaneous communicative situations, the more learners are pushed to communicate in 
the target language, the sooner the process of language acquisition will be activated.

3. Grammar teaching must take account of the sequences of natural acquisition. Individual phases cannot be skipped; trying to skip them regardless will put learners at risk of fossilisation, if not regression. It is entirely conceivable that grammar explanations and exercises can be helpful if they are given when the students have reached the corresponding acquisitional phase (in other words, when the prerequisites for the next phase are present). To what extent this actually facilitates or even speeds up acquisition still needs to be tested empirically.

4. Enlightened foreign language teachers will know how to distinguish different types of errors: those that can be avoided because they involve grammatical structures already acquired (generally these are careless errors anyway); the typical errors of exploration, which are the result of erroneous learner hypotheses, and finally errors beyond the learners' current acquisitional phase, where correction would be fruitless. Teachers will also realise that their students cannot and should not avoid errors, because they are a necessary consequence of the dynamics of forming and revising hypotheses. Avoiding errors on principle would mean blocking the process of acquisition (cf. Petit 1989).

5. Finally, enlightened foreign language teachers will try to tailor the grammar programme for individual students, as much as possible, to what they can effectively process at their current stage of acquisition. In this way the weaker students will not become fossilised and the more advanced ones will not be bored. The table of learning phases (Diehl et al 2000:364, see above) allows teachers to determine what their students can and cannot achieve.

For some years now, schools in Geneva have worked towards implementing the findings of the DiGS project in the German language classroom. Curricula have been adapted, all teachers of German have received in-service courses about the project and its results, the acquisitional sequences for German grammar are covered in teacher 
training courses and various groups are developing materials for individualised courses based on DiGS criteria (Brunschwig 1999). Admittedly established habits cannot be changed over night and what really happens in the classroom is outside the researchers' sphere of influence. The best thing their research findings have achieved is to offer those teachers who are dissatisfied with the status quo in teaching German a practical framework which enables them to make teaching grammar and thus the German language a less traumatic, more interesting and possibly even enjoyable experience for teachers and students alike, and in doing so achieve better outcomes than in the past. 